\title{
The production of haemoglobin by small pond Daphnia pulex: intraspecific variation and its relation to habitat
}

DIANA L. ENGLE Division of Biological Sciences, The University of Michigan, Ann Arbor, Michigan, U.S.A.

SUMMARY. 1. Haemoglobin production was measured for two populations of Daphnia pulex, one from a temporary pond (GR Pond) and one from a permanent pond (Rash Pond). Surface water in Rash Pond remains high in oxygen, while by late summer very little oxygen remains in GR Pond. Haemoglobin synthesis was induced in the laboratory by artificial oxygen deficiency.

2. Reproductive state influenced the level of haemoglobin in Daphnia. Females with parthenogenetic eggs had higher total body haemoglobin than ephippial females. Clutches laid by pale Daphnia immediately before exposure to low oxygen conditions were aborted. Offspring produced by haemoglobin-rich females later in the treatment survived.

3. Haemoglobin production was higher for Rash Pond Daphnia. Visual predators exist in GR Pond, but are absent in Rash Pond. Also, Daphnia are smaller in GR Pond. Visual predation may have selected against high levels of haemoglobin in the temporary pond. Thus oxygen availability in nature is not necessarily a good predictor of haemoglobin production by Daphnia.

4. Feeding behaviour was altered in low oxygen conditions. Browsing was dominant in low oxygen treatments while Daphnia in control treatments filtered algae normally. Browsing may increase access to sedimented iron necessary for haemoglobin synthesis.

\section{Introduction}

Daphnia increase the synthesis of haemoglobin when low oxygen conditions are encountered. Elevated levels of haemoglobin prolong survival, increase swimming and feeding activity, speed development of eggs, and allow increases in clutch size (Fox, 1948; Fox, Gilchrist

Correspondence: Diana L. Engle, Division of Environmental Research, Academy of Natural Sciences of Philadelphia, 19th and the Parkway, Philadelphia, Pennsylvania 19103, U.S.A.
\& Phear, 1951; Kring \& O'Brien, 1976; Heisey \& Porter, 1977). Species of Daphnia may vary considerably in the ability to synthesize haemoglobin (Chandler, 1954; Fox, 1948; Green, 1956). These differences are not necessarily associated with different levels of oxygen stress in nature. Often, two species from the same habitat display variation in haemoglobin content. Green (1956) proposed three explanations for this phenomenon. First, behavioural differences may separate the two species spatially such that they encounter different oxygen 
conditions. Second, a physiological difference, such as in metabolic rate, might stimulate one species to produce more or less haemoglobin than another. Third, although two species may occupy the same microhabitat and have similar physiologies, there may exist inherent, perhaps genetic, differences in ability to respond to low oxygen.

Intraspecific variation in haemoglobin content has also been noted in some habitats. Prepas \& Rigler (1978) studied the vertical distribution of haemoglobin-rich and pale $D$. pulex over time in Lake Crawford, Ontario, and concluded that they comprised two spatially separate populations, the red Daphnia occupying a deeper stratum near an anaerobic chemocline where dissolved oxygen was $1 \mathrm{mgl}^{-1}$ or less. The vertical segregation of pale and red $D$. pulex was also observed in two thermally stratified lakes in southern Michigan (Third Sister Lake, R. M. Dorazio, pers. comm.; Hamilton Lake, C. E. Goulden, pers. comm.). It is not clear whether this type of stratification stems initially from behavioural differences or from genetic variation in abilities to produce haemoglobin.

The complexity of factors effecting haemoglobin synthesis by Daphnia makes it difficult to assess the extent to which patterns of oxygen availability determine this biosynthetic capability. In order to define the connection between habitat type and patterns of oxygen consumption, typical lake invertebrates have been contrasted with typical pond invertebrates (Berg, Jonasson \& Ockelman, 1962; Calow, 1975; Heisey \& Porter, 1977). This distinction may not always be valid. Small pond Daphnia may be exposed to very different oxygen regimes depending on whether they inhabit permanent or temporary bodies of water. Temporary pond Daphnia are often exposed to extremely low and unvarying oxygen levels during drying due to minimal water mixing, highly organic substrata and large bacteria populations (Moore \& Burn, 1968). Daphnia in permanent pond, however, are usually capable of occupying surface strata where dissolved oxygen is high. In this investigation, I compared haemoglobin production by two populations of Daphnia pulex, one from a temporary pond and one from a permanent pond. In this way 1 was able to test for intraspecific variation in haemoglobin production by one pond species of Daphnia and to see if such differences were correlated to oxygen availability in the two habitats.

\section{Materials and Methods}

Daphnia pulex Leydig were collected from two ponds in southeastern Michigan in mid-August 1982. The first pond, Rash Pond, is a permanent shallow body of water in an abandoned gravel pit located in the University of Michigan Mathaei Botanical Gardens, Ann Arbor, Michigan. It has a maximum depth of $2 \mathrm{~m}$ and a maximum area of $1000 \mathrm{~m}^{2}$ (Brambilla, 1980). At the time of sampling, dissolved oxygen in Rash Pond decreased from slightly below saturation $\left(7.5 \mathrm{mg} \mathrm{l}^{-1}\right)$ at the surface to as low as $1 \mathrm{mgl}^{-1}$ near the bottom. The second pond, GR Pond, is a heavily shaded temporary pond approximately $300 \mathrm{~m}^{2}$ in area located in the E. S. George Reserve, Pinckney, Michigan. It forms from run-off and precipitation during spring thaw and dries completely by late summer. Its substratum is thickly covered with leaf litter and decaying material. Its depth in midAugust 1982 was less than $60 \mathrm{~cm}$. Dissolved oxygen in GR Pond was less than $1 \mathrm{mgl}^{-1}$ throughout the water column.

Laboratory clones of $D$. pulex were started by isolating ovigerous females into beakers of filtered pond water (Whatman glass fibre, GF-F). Chlamydomonas reinhardtii Dang from a unialgal batch culture (grown at $20^{\circ} \mathrm{C}$ under 16:8 LD cool fluorescent light) was provided as food. Over several days the clones were acclimated to an artificial medium at $\mathrm{pH}$ 7.6 (MWC medium, see Lehman, 1976). Animals were also kept at $20^{\circ} \mathrm{C}$ on a $16: 8 \mathrm{LD}$ light cycle. Later, an experimental stock for each population was begun by raising twenty-four neonates (each from a different clone) in individual shell vials with $15 \mathrm{ml}$ of $\mathrm{MWC}$ medium and $C$. reinhardtii at a concentration of $1 \times 10^{5}$ cells $\mathrm{ml}^{-1}$. The neonates were transferred each day to fresh algal suspension (hereafter called culture medium).

\section{Haemoglobin induction experiments}

Three consecutive experimental trials were carried out on each population. Each trial consisted of a pre-treatment period of 10 days 
in which neonates were raised to maturity in near-saturated oxygen conditions followed by a treatment period of 10 days in which the adult Daphnia were subjected to low oxygen. Total body haemoglobin was assayed on day 21 of each experimental trial.

The first offspring produced by the experimental stocks served as the source of neonates for Trial 1 . The neonates were pooled and randomly sorted into $600 \mathrm{ml}$ beakers of culture medium (forty neonates per beaker). Every $24 \mathrm{~h}$ an aliquot from each pretreatment container was measured for absorbance at $500 \mathrm{~nm}$ with a Hitachi Model 100-80 spectrophotometer to determine algal density. C. reinhardtii was then added to readjust food concentration to $1 \times 10^{5}$ cells $\mathrm{ml}^{-1}$. Offspring produced by Daphnia in the pretreatment beakers (typically on day 9 or 10 ) in trial 1 and trial 2 were pooled and served as the source of neonates to begin trials 2 and 3 , respectively.

On day 10 , treatment bottles were prepared. Glass reagent bottles $(500 \mathrm{ml})$ were filled with culture medium. For low oxygen treatments, dissolved oxygen was reduced to $3 \mathrm{mg} \mathrm{l}^{-1}$ by bubbling the culture medium with compressed $\mathrm{N}_{2}$. An oxygen electrode (Orion Research Model 97-08) inserted into the neck of the bottles measured dissolved oxygen during bubbling. Low oxygen bottles were kept firmly stoppered. Control bottles were not bubbled and were left unstoppered to allow exchange with room air. Adult Daphnia from each set of pretreatment beakers were pooled and randomly transferred into treatment bottles (two low oxygen bottles, one control bottle) until each contained thirty-five animals. All bottles were kept at $20^{\circ} \mathrm{C}$ and in the dark to prevent photosynthesis.

Daphnia were kept in treatment bottles for 10 days. Every $24 \mathrm{~h}$, algal concentration in each treatment bottle was measured and adjusted $\left(1 \times 10^{5}\right.$ cells $\left.\mathrm{ml}^{-1}\right)$ as described for pretreatment beakers. Any carcasses, moults, and shed ephippia were removed. When necessary, I readjusted dissolved oxygen in the low oxygen bottles with a special bubbling device (see Fox, 1948) that allowed circulation of culture medium past a stream of nitrogen gas, but protected animals from contact with bubbles. In the same way, air was gently bubbled into control bottles daily for a few minutes to maintain oxygen at near saturation. After 5 days, dissolved oxygen was reduced to $2 \mathrm{mgl}^{-1}$ in low oxygen bottles for the rest of the treatment period.

On day 21 of each trial, all adult Daphnia were removed from treatment bottles, measured with an ocular micrometer (head shield to base of tail spine) and sorted into vials with respect to four reproductive states:

Eggs: presence of eggs or early embryos (head bulge, but no eye spots) in the brood chamber.

$\mathrm{Mid} / \mathrm{Late}$ : presence of mid embryos (double red eye spots) or late embryos in the brood chamber.

Barren: not reproducing, ovaries unenlarged and inactive.

Ephippial: stages of formation, or presence, of ephippium.

Females with enlarged ovaries that had moulted, but not yet laid eggs, were included in the with-eggs category. Total body haemoglobin was measured using a modification of the carboxyhaemoglobin method of Crider, Wilhm \& Harmon (1982). Samples consisted of three to fifteen Daphnia of the same reproductive state. state.

Length-dry weight relationships were established for each population for three categories of adult animals from the laboratory clones: fecund (eggs or embryos); barren; and ephippial (see Bottrell et al., 1976; Richman, 1958). All Daphnia used in the analysis had full guts and a high lipid content (visual index; Tessier \& Goulden, 1982). Dry weights of single animals were found to the nearest $0.01 \mathrm{mg}$ on a Cahn Model 29 Electrobalance. The resulting regression formulae allowed me to predict individual dry weight from length with an average standard error of $18 \%$. Each haemoglobin value was divided by the total dry weight of Daphnia included in the same and converted to nmol $\mathrm{HbCO}$ per mg dry weight.

\section{Results}

\section{Haemoglobin content of Daphnia}

Levels and patterns of haemoglobin production within each population were similar in trials 1-3. Therefore, for each population the results of the three trials were pooled. Kruskall 


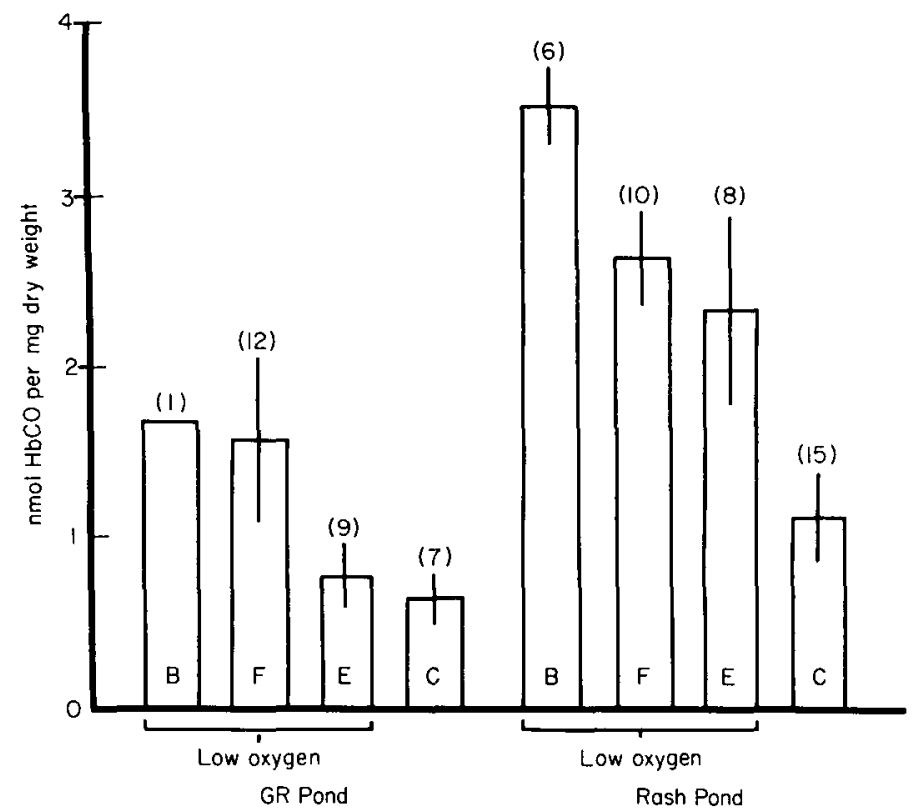

FIG. 1. Mean haemoglobin content (nmol carboxyhaemoglobin $\mathrm{mg}^{-1}$ dry weight) for barren (B), fecund (F), ephippial (E) and control (C) Daphnia pulex. Results shown are those pooled from all three experimental trials. The number of samples assayed for each category is given in parentheses. Error bars represent $95 \%$ confidence intervals around the means.

Wallis tests (Sokal \& Rohlf, 1969) indicated that for both ponds there was no significant difference in haemoglobin content between females with eggs and females with mid or late embryos (for GR Pond, $P=0.570$; for Rash Pond, $P=0.088$ ). These two categories were therefore pooled and treated as one category, 'Fecund,' in all subsequent analyses. Similar tests showed that reproductive state (fecund, barren, ephippial) had no significant effect on the haemoglobin content of Daphnia in control treatments (for GR Pond, $P=0.448$; for Rash Pond, $P=0.860$ ). These categories were also pooled for each population and treated as one, 'Control' in further analysis. Overall trends in haemoglobin content with respect to reproductive state were the same for Rash Pond and GR Pond (Fig. 1). Rash Pond Daphnia produced significantly more haemoglobin than those from GR Pond in every category (fecund, $P=0.006$; ephippial, $P=0.0005$; control, $P=0.001$ ).

TABLE 1. Length of adult (assayed) Daphnia pulex. Trials 1-3 pooled.

\begin{tabular}{llccl}
\hline Population & Category & No. of samples & Mean length $(\mathrm{mm})$ & Standard error \\
\hline GR Pond & Fecund & 12 & 2.121 & 0.026 \\
& Barren & 1 & $(2.030)$ & - \\
& Ephippial & 9 & 1.997 & 0.024 \\
& Control & 7 & 2.027 & 0.035 \\
\multirow{5}{*}{ Rash Pond } & & & & \\
& Fecund $^{*}$ & 10 & 2.344 & 0.040 \\
& Barren $^{*}$ & 6 & 2.216 & 0.026 \\
& Ephippial $^{\dagger}$ & 8 & 2.118 & 0.033 \\
& Control $^{\ddagger}$ & 14 & 2.237 & 0.061 \\
\hline
\end{tabular}

${ }^{*}$ Significantly larger than GR Fecund: Kruskall Wallis, $\chi^{2}=10.44, P=0.0012$.

${ }^{\dagger}$ Significantly larger than GR Ephippial: Kruskall Wallis, $\chi^{2}=5.33, P=0.0209$.

¥Significantly larger than GR Control: Kruskall Wallis, $\chi^{2}=4.06, P=0.0439$. 


\section{GR Pond}

Fecund females had a significantly higher haemoglobin content than either ephippial $(P=0.001)$ or control females $(148 \%$ increase, $P=0.0004)$. The haemoglobin content of ephippial females was not significantly different from that of the control females $(24 \%$ increase, $P=0.153$ ). The single sample of barren females falls within one SE of the mean haemoglobin content for fecund females.

\section{Rash Pond}

Barren females had the highest mean haemoglobin content and were significantly different from fecund $(P=0.009)$, ephippial $(P=0.002)$, and control Daphnia $(P=0.001)$. Fecund females had the next-highest levels of haemoglobin. Although they contained significantly more haemoglobin than control animals ( $134 \%$ increase, $P=0.0001$ ), they were not significantly different from ephippial females $(P=0.155)$. In contrast to the results from GR Pond, ephippial females from Rash Pond had a significantly higher haemoglobin content than control females ( $108 \%$ increase, $P=0.001)$.

\section{Length of Daphnia}

Low oxygen treatments. In both populations fecund females formed the largest size class and ephippial females were the smallest (see Table 1). Kruskall Wallis tests (Sokal \& Rohlf, 1969) showed that fecund females from GR Pond were significantly larger than ephippial females $(P=0.004)$ from the same pond. Rash Pond fecund females were significantly greater in length than both barren $(P=0.017)$ and ephippial females $(P=0.004)$. Daphnia from Rash Pond were significantly larger than GR Pond Daphnia in every category considered.

Control treatments. Daphnia assayed from the control treatments for both populations were comprised of similar percentages of fecund, ephippial and barren females. Within both groups of control animals, the same trends for body size were observed. Fecund females were largest, barren females were next-largest and ephippial females were smallest. Statistical tests on length were not performed between reproductive categories within control groups. However, when analysed as two groups, Rash Pond control females were significantly larger than GR Pond control females (see Table 1).

\section{Weight of Daphnia}

Dry weight followed the same trends as body length with one exception: GR Pond ephippial Daphnia weighed more on average $(165 \mu \mathrm{g})$ than Rash Pond ephippial Daphnia $(76 \mu \mathrm{g})$. In every other category, however, Rash Pond Daphnia exceeded GR Pond Daphnia in weight.

\section{Discussion}

\section{Maternal haemoglobin and egg development}

The level of haemoglobin in the blood of parthenogenetically reproducing Daphnia fluctuates over the course of each instar. Up to one-third of an ovigerous female's haemoglobin passes into ovaries and eggs just before moulting takes place and eggs are laid into the brood chamber (Fox, Hardcastle \& Dresel, 1949; Green, 1956; Dresel, 1948). As the eggs develop, more haemoglobin is produced by the female. Haemoglobin is thus lowest in a female early in an instar and greatest late in an instar just before mature embryos are released. In this study I detected less haemoglobin in females carrying eggs (or about to lay eggs) than in females carrying mid or late embryos. This was true in both low oxygen and control bottles, but the differences were not statistically significant. The average haemoglobin content of ephippial females was lower than that of fecund females. Absence of haemoglobin in ephippial eggs (Fox, 1948) may have contributed to this difference.

Within the first 3 days of oxygen deprivation, I observed that almost all moulting was accompanied by abortion of undeveloped eggs or embryos. This suggests that maternal haemoglobin is necessary for development of parthenogenetic eggs under low oxygen conditions. The aborted clutches were laid before the females had elevated levels of blood haemoglobin and did not receive the same reserve of maternal haemoglobin as later clutches did. Development of these first eggs may have been hindered by inadequate respiration once the parents were placed in low 
oxygen conditions (Fox, 1948). Offspring produced by haemoglobin-rich females later in the treatment period were vigorous and usually highly pigmented.

\section{Haemoglobin content and metabolic rate}

Variation in haemoglobin production among Daphnia in uniform oxygen conditions may sometimes be explained by differences in metabolic rate, related to the age, size and sex of individuals (Green, 1956). The inverse relationship between respiration rate and body size among Daphnia (Hoshi \& Yajima, 1970) suggests that haemoglobin production will also be inversely related to body size. Green (1956) used this relationship to explain his observation that when pairs of pond-dwelling species of Daphnia were compared in low oxygen tests, the smaller species in each pair produced a higher concentration of haemoglobin. Others have studied the relationship between metabolic rate and haemoglobin content by varying temperature (Kobayashi, 1974, 1981; Hoshi et al., 1978). Fox \& Phear (1953) discovered that when oxygen concentrations were held constant, Daphnia synthesized more haemoglobin at a higher temperature (presumably due to a higher metabolic rate).

In my experiment, the relationship between body size and haemoglobin synthesis (Green, 1956) did not hold true. Rash Pond Daphnia were significantly larger (Table 1) in every category than GR Pond Daphnia-yet they produced more, not less, haemoglobin in low oxygen conditions. (All assayed animals were of the same age and sex.) Body sizes cannot account for differences between reproductive categories. Overall, ephippial females were lowest in body length and weight, yet they displayed the lowest haemoglobin levels. Also, barren Daphnia, which produced the highest haemoglobin levels, were intermediate in length and dry weight.

It is not clear why low oxygen conditions induced a greater increase in haemoglobin content for ephippial females from Rash Pond (108\% increase relative to control or 'basal' level) than for GR Pond ephippial females (24\% increase). Although ephippial females from Rash Pond exceeded those from GR Pond in length, they weighed less. Their greater response to low oxygen conditions may have been due, in part, to a higher metabolic rate.

\section{Feeding behaviour}

A striking difference in feeding behaviour was observed between Daphnia in low oxygen conditions and those in control conditions. Daphnia in the control bottles were usually evenly distributed in the water column and appeared to filter the culture medium in a normal fashion. In contrast, the Daphnia in low oxygen bottles foraged on the bottoms and sides of their treatment bottles. At the end of any $24 \mathrm{~h}$ period nearly $100 \%$ of the animals in low oxygen bottles would be clinging firmly to or combing the walls of their container. Vigorous beating of filtering appendages dislodged particles of detritus, which were usually collected and ingested. If disturbed by bubbling activity, the Daphnia only temporarily invaded the water column, quickly adhering to glass surfaces again. The appearance of the test bottles supported these observations. The bottoms of control bottles were consistently covered with an undisturbed layer of sedimented algae and the sides grew cloudy with algal wall growth. In contrast, wall growth was removed in low oxygen bottles, a thin deposit of faecal pellets lined the bottom, and undigested algal material was absent.

The term 'browsing' has been adopted by MacMahon \& Rigler (1963) to contrast this foraging behaviour with normal suspension feeding. Data on the conditions under which Daphnia become bottom feeders suggests that browsing is an adaptation to bodies of water in which pelagial food sources vary in time but where the benthos provides a highly caloric supply of bacteria-rich sedimented or detrital food (Papinska, 1981; Rodina, 1963). Horton et al. (1979) studied the relationship between food supply and browsing in D. pulex and found that when the concentration of suspended algae dropped below $1 \times 10^{4}$ cells $\mathrm{ml}^{-1}$, up to $70 \%$ of the animals sunk out of the water column to forage in bottom sediments. The high haemoglobin content of Daphnia in low oxygen conditions may have enabled them to remove algae at rates 2-2.5 times greater than the pale Daphnia in control conditions (Kring \& O'Brien, 1976). Food concentration in low oxygen bottles may have decreased during each $24 \mathrm{~h}$ period to some critical threshold 
value more rapidly than in control bottles and may have stimulated the change in feeding behaviour.

A shift from filter feeding to browsing may actually promote haemoglobin synthesis by cladoceran zooplankton. Daphnia are clearly able to ingest colloidal precipitates of ferric hydroxide and addition of iron compounds has been shown to increase haemoglobin production in low oxygen conditions (Gellis \& Clark, 1935; Fox \& Phear, 1953; Hoshi \& Kobayashi, 1972). In laboratory cultures and in nature, iron in the water column typically sinks as fine precipitates of ferrous and ferric hydroxide (Fox \& Phear, 1953; Wetzel, 1975). Browsing by Daphnia on the bottoms of ponds or lakes may increase their access to a source of inorganic iron less available through feeding activity higher in the water column.

\section{Haemoglobin content and habitat differences}

Based on patterns of oxygen availability in the ponds, the results of my experiment are surprising. In late summer, Daphnia in GR Pond have no oxygenated refuge and must survive nearly anoxic conditions in order to complete the production of resting eggs. Daphnia in Rash Pond, however, are capable of visiting surface waters where oxygen content is high. It is reasonable to expect that haemoglobin production would be greater in GR Pond Daphnia. However, Rash Pond Daphnia surpassed GR Pond Daphnia in haemoglobin synthesis, in both low and high oxygen (control) conditions. This suggests that a difference, perhaps genetically based, may exist in the basal level of haemoglobin in $D$. pulex from the two localities (Fox, 1948; Green, 1956: Heisey \& Porter, 1977). What difference, other than oxygen regime, might underlie the differences in haemoglobin production by Daphnia from GR Pond and Rash Pond?

Visual predation may have selected against high basal levels of haemoglobin in GR Pond. In summer, GR Pond supports a population of salamander larvae (Ambystoma) which prey visually on Daphnia (Brambilla, 1980). Rash Pond, however, contains no visual predators. In many cases, haemoglobin content in Daphnia may be directly related to visual predation. Vertebrate predators detect red Daphnia more quickly and at greater distances than pale
Daphnia (Vinyard \& O'Brien, 1975). Landon \& Stasiak (1983) suggested that the absence of visual predators in Arco Lake allowed $D$. pulex to maintain a relatively high basal haemoglobin level above the thermocline.

In general, visual predation tends to exclude large zooplankton from lakes and ponds (Brooks, 1968; Brooks \& Dodson, 1965; Dodson, 1970; Kerfoot, 1974; Wells, 1970). Predation experiments by Brambilla (1980) indicate that salamander larvae prefer the largest $D$. pulex available. The fact that GR Pond Daphnia were significantly smaller than Rash Pond Daphnia supports the suggestion that visual predation is an important selective factor in GR Pond.

The results of this experiment indicate that when races of the same species of Daphnia differ in the ability to produce haemoglobin in low oxygen conditions, the differences will not necessarily correspond to patterns of oxygen availability in nature. Habitat variables (such as oxygen supply, temperature, and visual predation) may interact in complex ways with phy. siological variables (such as metabolic rate) in determining the extent to which Daphnia will synthesize haemoglobin. Additionally, it is not clear what role genetic differences, perhaps involving the mechanism for haemoglobin induction, may play in regulating this biosynthetic trait.

\section{Acknowledgments}

I am grateful to Dr J. T. Lehman for guidance and support throughout this project. I also thank P. Rago, R. Dorazio, J. Weiland and S. Seitzinger for their interest and helpful criticism. The manuscript benefited from the comments of an anonymous reviewer. This work was supported by National Science Foundation Grant DEB8116428 to John T. Lehman

\section{References}

Berg K., Jonasson P.M. \& Ockelmann K.W. (1962) The respiration of some animals from the profundal zone of a lake. Hydrobiologia, 19, 1-39.

Bottrell H.H., Duncan A., Gliwicz Z.M., Grygierek E., Herzig A., Hillbricht-Ilkowska A., Kurasawa H., Larsson P. \& Weglenska T. (1976) A review of some problems in zooplankton production studies. Norwegian Journal of Zoology, 24, 419456. 
Brambilla D.J. (1980) Seasonal changes in size at maturity in small pond Daphnia. Evolution and Ecology of Zooplankton Communities (Ed. W. C. Kerfoot). The University Press of New England, Hanover, New Hampshire.

Brooks J.L. (1968) The effects of prey size selection by lake planktivores. Systematic Zoology, 17, 272-291.

Brooks J.L. \& Dodson S.I. (1965) Predation, body size, and composition of plankton. Science, 150, 28-35.

Calow P. (1975) The respiratory strategies of two species of freshwater gastropods (Anclus fluviatilis Mull and Planorbis contortus Linn) in relation to temperature, oxygen, concentration, body size and season. Physiological Zoology, 48, 114-130.

Chandler A. (1954) Causes of variation in the haemoglobin content of Daphnia (Crustacea: Cladocera) in nature. Proceedings of the Zoological Society of London, B, 124, 625-630.

Crider J.Y., Wilhm J. \& Harmon H.J. (1982) Effects of napthalene on the haemoglobin concentration and oxygen uptake of Daphnia magna. Bulletin of Environmental Contamination and Toxicology, 28, 52-57.

Dresel E.I.B. (1948) Passage of haemoglobin from blood into eggs of Daphnia. Nature, 162, 736737

Dodson S.I. (1970) Complementary feeding niches sustained by size-selective predation. Limnology and Oceanography, 15, 131-137.

Fox H.M. (1948) The haemoglobin of Daphnia. Proceedings of the Royal Society, B, 135, 195212.

Fox H.M., Hardcastle S.H. \& Dresel E.I.B. (1949) Fluctuations in the haemoglobin content of Daphnia. Proceedings of the Royal Society, B, 136, 388-399.

Fox H.M., Gilchrist B.M. \& Phear E.A. (1951) Functions of haemoglobin in Daphnia. Proceedings of the Royal Society, B, 138, 514-528.

Fox H.M. \& Phear E.A. (1953) Factors influencing haemoglobin synthesis by Daphnia. Proceedings of the Royal Society, B, 141, 179-189.

Gellis S.S. \& Clark G.L. (1935) Organic matter in dissolved and in colloidal form as food for Daphnia magna. Physiological Zoology, 8, 127-137.

Green J. (1956) Variation in the haemoglobin content of Daphnia. Proceedings of the Royal Society, B, 145, 214-232.

Heisey D. \& Porter K.G. (1977) The effect of ambient oxygen concentration on filtering and respiration rates of Daphnia galeata mendotae and Daphnia magna. Limnology and Oceanography, 22, 839-845.

Horton P.A., Rowan M., Webster K.E. \& Peters R.H. (1979) Browsing and grazing by cladoceran filter feeders. Canadian Journal of Zoology, 57, 206-212.

Hoshi T. \& Kobayashi K. (1972) Studies on the physiology and ecology of plankton. XXVI. Promotion of haemoglobin synthesis by iron in Daphnia magna cultured under low oxygen conditions. Science Reports of Niigata University, Series D, 9, $55-62$.

Hoshi T., Kobayashi M., Umemura S. \& Sato N.
(1978) Notes on haemoglobin and respiration of Daphnia magna in relation to temperature and $\mathrm{O}_{2}$-content of water and medium. Science $\mathrm{Re}$ ports of Niigata University, Series D, 15, 15-23.

Hoshi T. \& Yajima T. (1970) Studies on the physiology and ecolgy of plankton. XXIV. Possible role of blood haemoglobin induced by low oxygen culture in the respiration of Daphnia magna. Science Reports of Tohoku University, Series 4, 7, 107-115.

Kerfoot W.C. (1974) Egg-size cycle of a cladoceran. Ecology, 55, 1259-1270.

Kobayashi M. (1974) Oxygen consumption of Daphnia magna. Science Reports of Niigata University, Series D, 11, 1-10.

Kobayashi M. (1981) Influences of haemoglobin concentration and temperature on oxygen uptake of Daphnia magna under low oxygen concentration. Comparative Biochemistry and Physiology, 69A, 679-682.

Kring R.L. \& O'Brien W.J. (1976) Effects of varying oxygen concentration on the filtering rate of Daphnia pulex. Ecology, 57, 808-814.

Landon M.S. \& Stasiak R.H. (1983) Daphnia haemoglobin concentration as a function of depth and oxygen availability in Arco Lake, Minnesota. Limnology and Oceanography, 28, 731-737.

Lehman J.T. (1976) Photosynthetic capacity and luxury uptake of carbon during phosphate limitation in Pediastrum duplex (Chlorphyceae). Journal of Phycology, 12, 190-193.

MacMahon J.W. \& Rigler F.H. (1963) Mechanisms regulating the feeding rate of Daphnia magna Straus. Canadian Journal of Zoology, 41, 321332.

Moore W.G. \& Burn A. (1968) Lethal oxygen thresholds for certain temporary pond invertebrates and their applicability to field situations. Ecology, 49, 349-351.

Papinska K. (1981) Occurrence of filtering Crustacea in the near bottom and pelagial water of the Mikolajskie Lake. Hydrobiologia, 83, 411-418.

Prepas E. \& Rigler F.H. (1978) The enigma of Daphnia death rates. Limnology and Oceanography, 23, 970-988.

Richman S. (1958) The transformation of energy by Daphnia pulex. Ecological Monographs, 28, 273291.

Rodina A.G (1963) Microbiology of detritus of lakes. Limnology and Oceanography, 8, 388-393.

Sokal R.R. \& Rohlf F.J. (1969) Biometry. W. H. Freeman, San Francisco.

Tessier A.J. \& Goulden C.E. (1982) Estimating food limitation in cladoceran populations. Limnology and Oceanography, 27, 707-717.

Vinyard G.L. \& O'Brien W.J. (1975) Dorsal light response as an index of prey preference in Bluegill (Lepomis macrochirus). Journal of the Fisheries Research Board of Canada, 32, 18601863.

Wells L. (1970) Effects of alewife predation on zooplankton populations in Lake Michigan. Limnology and Oceanography, 15, 556-565.

Wetzel R.G. (1975) Limnology. Saunders College Publishing, Philadelphia.

(Manuscript accepted 14 February 1985) 
This document is a scanned copy of a printed document. No warranty is given about the accuracy of the copy. Users should refer to the original published version of the material. 